\title{
A Stylistic Analysis of Complexity in William Faulkner's "A Rose for Emily"
}

\author{
Israa' Burhanuddin Abdurrahman \\ English Department, College of Education for Women, Tikrit University, Iraq \\ E-mail: say_awab@yahoo.com
}

Doi:10.7575/aiac.alls.v.7n.4p.220

URL: http://dx.doi.org/10.7575/aiac.alls.v.7n.4p.220
Received: 11/04/2016

Accepted: $30 / 06 / 2016$

\begin{abstract}
Applying a stylistic analysis on certain texts refers to the identification of patterns of usage in writing. However, such an analysis is not restricted just to the description of the formal characteristics of texts, but it also tries to elucidate their functional importance for the interpretation of the text. This paper highlights complexity as a hallmark of a stylistic analysis in $A$ Rose for Emily, a short story by William Faulkner (1897-1962). The analysis is done by adopting Halliday's (1985) approach to analyzing complexity in sentence structure; and Lauer, et al's (2008) approach to analyzing narrative from a macro perspective in relation to the story acts. The analysis rests upon the assumption that since form conveys meaning, Faulkner's multilayer usage of complexity is extremely functional. This paper tries also to detect and prove that stylistic complexity is manipulated to convey the main themes, events, and successfully leads to identify the distinctive structure of this story.
\end{abstract}

Keywords: Style, Stylistic Complexity, Hypotactic, Paratactic, Functional

\section{Introduction}

Stylistics in literature is the study of the writer's style, i.e., the use of language in literature to examine the general features of language as a medium of literary expressions. It is a branch of general linguistics that focuses on style (i.e. the manner of a speaker's or writer's linguistic expression), particularly in works of literature (Leech, 1969:1). Stylistic analysis in literary studies is usually made for the purpose of commenting on quality and meaning in a text. It is the study of style used in literary language and the effect the writer wishes to communicate to the reader. It attempts to create a correlation between certain literary effects or themes and linguistic 'triggers' wherever relevant (ibid: 373 ). This demonstrates that stylistics is concerned with interpreting the literary effects of linguistic elements and their importance for the whole signification of the text.

The concepts of 'style' and 'stylistic variation' in language rest upon the general assumption that within the language system, the same content can be encoded in more than one linguistic form. Style may be regarded as a choice of linguistic means; as deviation from a norm; and as comparison. Accordingly, narrative language may adopt functional complexity structure as a special choice of style developing hence a leading guide to configure many perspectives in the analysis.

Shklovsky (1917) (cited in Fabb, 2002: 2) regards the inherent complexities and multiplicities of literary form as aesthetic. He says that, "the technique of art is to make objects unfamiliar, to make forms difficult, to increase the difficulty and length of perception because the process of perception is an aesthetic end in itself and must be prolonged". Hardy (ibid: 3) further comments that irregularities can be produced purposefully as art and operated as to give more appeal than strict conventionalities.

Stylistic complexity has been approached by many scholars in the literature. One of the earliest and still most famous such studies was that presented by Halliday (1971), in which he investigated transitivity as an unfamiliar patterning in William Golding's 1955 novel, The inheritors. Halliday tries his best to improve his knowledge of how language works and how linguistic structure is utilized literally. He develops his analysis of texts into an analysis of sentence structure. He (ibid: 360) points out that the syntax of a novel/story is part of that literary work. In a similar vein, Carter (1997) for example, explores the syntactic relations in Joseph Conrad's 1907 novel The secret agent, who strives to bridge the syntactic/stylistic connection in his analysis. Another work is that of Fabb's (2004) in dealing with linguistic complexity represented in recursion- or narrative embedding as he calls it, in Margaret Elphinstone's 2001 novel The Sea Road. He states that knowing the text structure- sentence structure, acts structure, and the relation between them as a whole, makes the analyst more sensitive to the theme the writer wants to convey; to the nature of the characters; or to main structure of the literary work. He adds that "to be able to isolate elements of language enables the analyst to observe things that otherwise are below the threshold of attention". In the same way, Alemu (2015: 35) proposes a stylistic analysis of O. Henry's 1904 Last Leaf and (1907) the Furnished Room. He investigated syntactic repetitions a s a form of complexity in these short stories. 
In fact, managing up detailed analysis at the micro-linguistic level with a broader view of the communicative context is the aim that many stylistic analyses are after; indeed it is this integrative direction that this paper is after.

\section{2. "A Rose for Emily"}

William Faulkner (1870-1932) is one of the most distinguished American writers. His most well-known, most widespread, and most anthologized short story, A Rose for Emily (1931) arises the terms 'Southern gothic and grotesque', the types of literature in which the general tone is that of despair, fear, and understated violence. The story is Faulkner's best example of these forms because it holds many dark images: a decaying mansion, a corpse, a murder, a mysterious servant who disappears, and, most horrible of all, as Volpe (2004: 291) comments, 'necrophilia' - an erotic or sexual attraction to corpses.

The central character is Miss Emily Grierson on whom most of the actions and discussions revolve. Miss Emily, as a symbolic character is portrayed in the story as an aristocratic woman. The community highly respects her and considers her as "a tradition, a duty" or, as the anonymous narrator represents her, a 'fallen monument' (Roberts, 1997: 6). This unnamed narrator details the strange circumstances of Emily's life and her odd relationships with her father, her lover, the town of Jefferson, and the horrible secret she hides. http://www.sparknotes.com/short-stories/a-rose-for emily/summary.html. However, the reader is finally shocked by finding out that this woman who is put on a pedestal by her community has not only poisoned her lover and killed him; moreover, she kept his corrupted corpse at her home and maintained sleeping by it. This reflects one of the most basic themes of the story: the unspeakable secrecy of aristocratic conservative class women.

\section{The Concept of Complexity in Stylistics}

Fabb (2002: 47) and (Clay: 2005, 87) argue that a complex narrative text holds the literary form in a variety of ways which are inherently complex. This complexity is sometimes straightforwardly detected and described in case of nonprojection; however, another kind of complexity would be less transparent to be revealed and described as projected, i.e. purposefully planned. As far as stylistics deals with the variation of style in use, the impact of complexity, whether predictable or not, increases in this regard. Complexity may reveal a lot by implicating sometimes the nature of the characters or hinting at the intended themes at other times. In this respect, many scholars have dealt with complexity in a variety of literary and non-literary texts resulting in the fact that structure complexity relates highly to the semantic intensity of a text. Fabb (2002: 212), accordingly, suggests that literary texts have two types of form: explicit and implicit or generated form. The first type being represented in the explicit meaning of narrative framework, the second in the meaning generated by the form of the literary work which needs to be identified by the reader. Stylistic complexity, as found mainly in the second type, shows itself in various shapes almost are in hierarchical relationship:

\subsection{Complexity of Sentence}

There have been attempts to argue that a whole narrative is like a whole sentence, and has the same kind of form like a sentence (Fabb, 2002: 212). However, in this paper the story is dealt with as constructed of many sentences, a type which can be detected formally. It manifests itself in sentence structure and sentence length, i.e. it works in tandem with the syntactic structure and the number of words in each sentence.

\subsubsection{Sentence Structure}

Bellard (1992:18) assures that sentence structure is a very 'revealing aspect of style'. To know about the structure of the sentence helps in describing a particular author's style; to recognize a character's behavior; to determine whether this style is formal or informal; and so on. He (ibid.: 40) further suggests that when there is an explicit relation between the stylistic structure and the plot, it will need less inference than if there is a contrastive relation between them leading to a sudden type of complexity. In a similar vein, Jucker (1992: 99) believes that stylistic complexity might result from sentence length which results in turn from pre and post modifications represented in the form of noun phrases. He suggests that such type of complexity requires a kind of inferencing behind the purpose of the author.

Dámová (2007: 48) states that the grammatical constructions of English are 'as distinctive as those of lexis'; and the complexity of sentences which might result out of long sentences, embedded clauses, or the unusual word order flows to the meaning of the text. Wales (2011: 207) and Furlong (2014: 78) also support that stylistic complexity is an important factor that gives rise to implicatures about the sophistication in the author's thoughts; and the variation in syntactic structure can suggest and/or reflect the real associations in the literary work. In fact, sentence complexity is frequently a sign of mental complexity.

In dealing with the complexity of sentence structure, M.A.K. Halliday's (1985) model of language is adopted. Halliday develops a type of grammar which has its effect internationally. His distinct way of handling grammatical explanations has the name of systemic functional grammar $(S F G)$. He believes that language is the resource of meaning (meaning potential), whose framework is highly systemic and highly related to its content.

In his $S F G$, Halliday (1985: 192-270) uses a special way to treat elements in grammar. According to him a sentence can be interpreted as a clause complex: a head clause together with other clauses that modify it. The sentence is evolved by expansion outward from the clause. The predicator is the most essential constituent of the clause; it is usually the case that the number of clauses in a sentence is equal to the number of predicators in that sentence, for example, the sentence: "He shouted, laughed, cried, and finally fell down the stairs" has four clauses, the missing subjects for the three subsequent clauses is understood to be ' $h e^{\prime}$ ' in the first clause. 


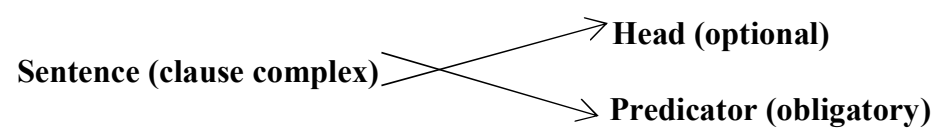

Figure 1. Sentence Main Constituents

In the $S F G$ there are three types of sentences:

1- A sentence with only one clause in is called a simple or simplex sentence.

2- A sentence with one or more independent clauses following the first clause is known as a compound sentence.

3- A sentence with one or more dependent clauses in relation to the main clause is known as a complex sentence.

An independent clause is also called a paratactic clause. Likewise, a compound sentence is known as a paratactic construction, and the complex sentence a hypotactic construction.

Halliday uses the term primary clauses for both the initiating clause of a paratactic construction and the main clause of a hypotactic construction; and secondary clauses for both the continuing clause of a paratactic construction and the dependent clause of a hypotactic construction as the following table displays:

Table 1. The structure of compound and complex sentences According to Halliday (1985)

\begin{tabular}{ccc}
\hline & Primary & Secondary \\
\hline Parataxis & 1(initiating) & 2 (continuing) \\
\hline Hypotaxis & $\alpha$ (dominant) & $\beta$ (dependent) \\
\hline
\end{tabular}

In table (1), Hypotactic structure is represented by Greek letters the first five of which are: $\alpha$ - alpha; $\beta$ - beta; $\gamma$ gamma; $\delta$ - delta; $\varepsilon$ - epsilon which are to be applied to longer embedded sentences with more than one independent clause. Paratactic structure, on the other hand is represented by Arabic numerals.

The initiating and continuing clauses of a paratactic structure can be written as ' 12 '. If there is another clause which is paratactically related to the continuing clause, the numbers ' 123 ' 2 are written. The dominant and dependent clauses of a hypotactic structure may also be represented in a similar manner (i.e. ' $\alpha \beta$ ' and ' $\alpha \beta \gamma$ '). It is possible for the secondary clause of a hypotactic structure to precede the primary clause, i.e. ' $\beta \boldsymbol{\alpha}$ ' may be correct. It is not possible for the secondary clause of a paratactic structure to come before the primary clause, i.e. '2 1 ' is incorrect. Secondary clauses in hypotaxis can precede the primary clauses $1 \beta 1 \alpha 2 \beta 2 \alpha$ instead of $1 \alpha 1 \beta 2 \alpha 2 \beta$ :

The parents had more leisure than they had known for years, and they promised wives

$1 \alpha \quad 1 \beta \quad 2 \alpha$

and daughters all manners of pleasant excursion as soon as the weather gets better.

$2 \beta$

The representation of the sentence will be: $1 \alpha 1 \beta \wedge 2 \alpha 2 \beta$. If the order of the sentence is reversed, the representation will be affected:

Other than they had known for years, the parents had more leisure; and as soon as the

$1 \beta \quad 1 \alpha$

weather gets better they promised wives and daughters all pleasant excursion.

$2 \beta \quad 2 \alpha$

Hence, the sentence representation will be: $\mathbf{1} \boldsymbol{\beta} \mathbf{1} \boldsymbol{\alpha}^{\wedge} \mathbf{2} \boldsymbol{2} \mathbf{2 \alpha}$, the $\left(^{\wedge}\right)$ mark is an indicator that one clause follows another in the given order.

3.1.2 Sentence Length

According to Gass (1985: 113), there's a soul in the sentence and length is one of its manifestations. He (ibid: 80) comments that sentence length is one aspect of style that reflects how a language lives on printed pages. Hişmanoğlu (2005: 56) highlights the importance of sentence length in literary works stating that long sentences have to do with perception and interpretation in a way that increases the factor of suspense. This leads further to establish "the tension that is necessary for a genuine exchange of ideas" (ibid).

Olson, et al (1985: 86) state that in English grammar sentence length refers to the number of words in a sentence. Nakagawa and Oquendo (2013: 2) believe likewise and suggest that sentence complexity is based on quantity insofar it affects quality. They also suggest that sentence length, which is measured by the number of its words, is one face of a multi-layered complexity in stylistics. Whereas Patton and Meara (1987: 286), on the other hand, suggest that sentence length is one way of measuring stylistic complexity that is done by considering the number of minor clauses in relation to the number of main clauses. In this work, the first view is adopted.

\subsection{Complexity of Acts}

The form of a literary text means how the text is structured. Certain forms are internationally agreed at and planned to be modeled in a certain way to fit their purpose or type especially in poetry. However, what matters is the form of acts in narrative, i.e. whether irregular or symmetrical. In this respect, Fabb (2002: 2) claims that literary forms are of different types many of which are types of implied form, i.e., form is at times concerned with other functions rather than 
being a merely framework of the literary text. Form may highly relate to content, as Glenn (2004: 27) states, in a way that "authors make form-related decisions that affect both the structural and thematic integrity of their work". She further adds that, in any literary text, the ultimate aim of the reader is to understand the content to make meaning, however, form should not be totally ignored because form is frequently driven by content. Indeed, the writer's selection of form in creating a literary text may reveal more than the content itself.

Considering symmetry of acts in narration, Perinbanayagam (1991: 164) states that "the symmetry of the thing told about and the telling form is important to secure realization of the effects sought". He also adds that an act form is "neither an appendix nor an afterthought. It is probably an integral part of the author's original plan and purpose. To support the idea, Glenn (2004: 32) maintains that many authors try to make the form, whether formal or informal, fit the function to help their readers have a better meaningful interaction with texts since the relationship between texts and readers is dynamic.

Dove (1989: 48) argues that the structure of narration is determined by suspense in terms of stages of narration, and the methods of development. He (ibid) adds that the idea of structure comprises the organization of "parts within the whole, the relationship of parts to the whole, and the relationships between individual parts themselves".

Accordingly, complexity of the story structure offers a bird's eye view of the structure in relation to the flow of actions and how the writer manipulates this relation in creating subtle narration techniques. In this respect, a macro level perspective of the structure is compromised with a bottom-up one by adopting Lauer, et al's (2008) narratological study. Lauer, et al (2008: 7) state that the essential categories used for analysis include mainly: framework of acts and time in narrative in relation to structure. The ultimate aim of their work is to check out how these factors are brought about and what type of linguistic structures they require. Lauer, et al (ibid: 7-8) suggest that these factors "presuppose a level of harmony between text structure and the reader's expectations"; and how the organization of the flow of information can trigger suspense, i.e. what structure information arrangements can generate suspense on the behalf of the readers. Lauer, et al name their approach in stylistic analysis the 'perspective structure' of narration which handles complexity of structure of narration in a holistic view.

\section{The Analysis}

The aim of a stylistic analysis is multifold, however, the aim that this paper is after is to identify the functional complex style structure the text is representative of. The analysis handles two levels:

\subsection{On the level of sentences}

In this level the three types of sentence are surveyed throughout the whole story:

a. Simple sentences

Faulkner's intelligent utilization of sentence type is highly obvious in A Rose for Emily. There are 60 simple sentences that are mainly functioned for basically three purposes:

1- Change of ------- time, e.g. act I sentences no. $11 \& 26$

------ point of view, e.g. act I sentences no. $31 \& 32$

------- place, e.g. act III sentence no. 4

2- Rapid happenings, e.g. act III sentence no. 6

3- Miss Emily's relationship with the people of her town reflecting her dignity and obstinacy, e.g. act II sentences no. $18 \& 19$.

\section{b. Complex sentences}

Complex sentences include Paratactic and Hypotactic constructions. Paratactic constructions are mainly used in direct speech, for instance, Act III sentences no. $15 \& 24$. They sometimes also refer to the addition of something. The total number of paratactic constructions is 66 .

On the other hand there are 96 hypotactic constructions in the story and Faulkner functions them intelligently to convey his theme. Since the theme is complex in nature, he needs a complex (round) character represented in Miss Emily and complex constructions represented in the hypotactic ones. Almost all hypotactic and para-hypotactic constructions are used to describe the complex psychological aspects of this character. Faulkner uses this complex structure as a type of technique to express man's position in the modern world. The complexity of Faulkner's narrative structures mirrors the complex lives we lead.

Concerning sentence length as another face of complexity, Faulkner uses sentences that vary in their lengths; however, the majority of them are lengthy ones. He exploits the longest sentence no. 4 / ACT V which is complex of a hypotactic construction to declare the climax. This sentence is represented in table (5) in the appendix as: $\boldsymbol{\alpha} \wedge \boldsymbol{\beta} \wedge \boldsymbol{\gamma} \wedge \boldsymbol{\varepsilon} \wedge \boldsymbol{\delta} \wedge \zeta \wedge \boldsymbol{\eta} \wedge \boldsymbol{\theta} \wedge \boldsymbol{\kappa} \wedge \boldsymbol{\lambda} \wedge \boldsymbol{\mu} \wedge \boldsymbol{v}$, consisting of 129 words!

Complexity of sentence structure and sentence length are best shown in brief in table (2) where the first column represent the act number, the second the sentence number, the third sentence length, the fourth sentence type whether simple or complex, and the fifth represents the sentence complexity type. More detailed tables that provide better descriptive illustrations are found in the appendix. 
Table 2. Sentence Length and Sentence Type Summarized

ACT NO. SENTENCE NO. SENTENCE SENTENCE TYPE COMPLEXITY

LENGTH SIMPLE/COMPLEX TYPE

\begin{tabular}{cccccccc}
\hline I & 46 & 812 & 21 & $/$ & 25 & $9 / 20$ \\
\hline II & 40 & 749 & 20 & $/$ & 24 & $18 / 25$ \\
\hline III & 44 & 657 & 8 & $/$ & 36 & $14 / 14$ \\
\hline IV & 44 & 1007 & 8 & $/$ & 36 & $20 / 27$ \\
\hline V & 16 & 483 & 3 & $/$ & 13 & $5 / 10$ \\
\hline TOTAL & 190 & 3708 & $60 / 134$ & $66 / 96$ \\
\hline
\end{tabular}

Table (2), as well as other tables in the appendix declare that lengthy, complex sentences are predominant over simple sentences as figure (2) manifests:

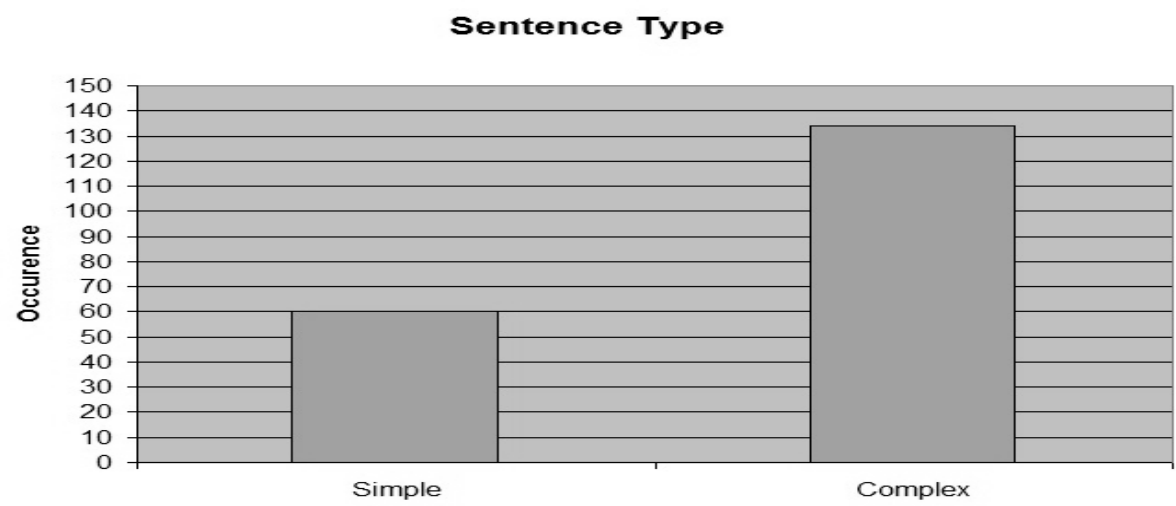

Figure 2. Sentence Type

Whereas figure (3) below shows a comparison between the two types of complex sentences (para \& hypo) and their frequency of occurrence in the story as Faulkner manipulates them.

\section{Complexity Type}

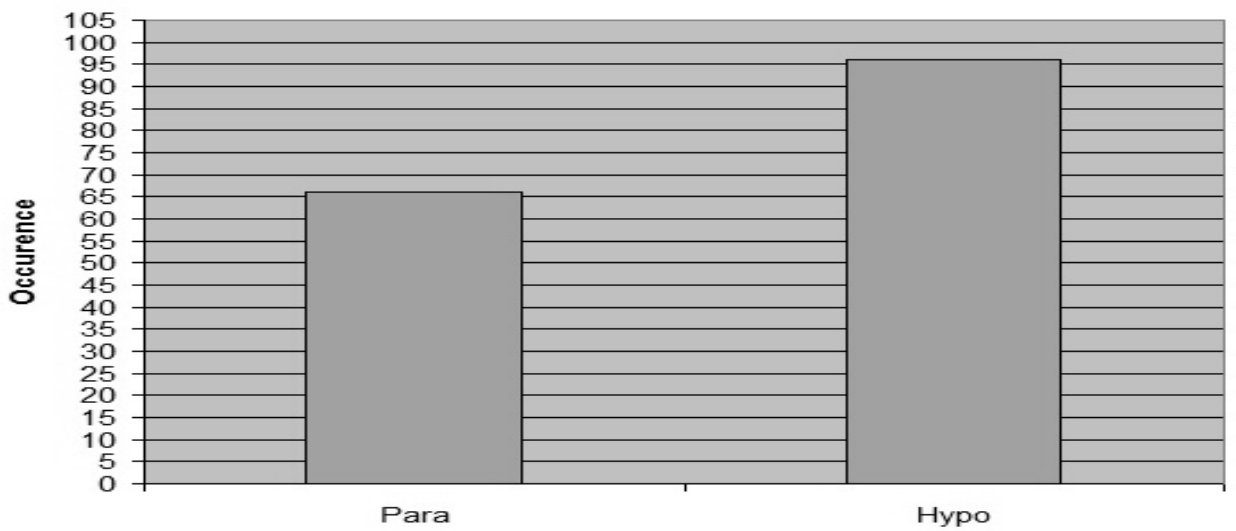

Figure 3. Complexity Type

Figures (2) and (3) reveal agreeably the prevailing structure of complexity in the story.

4.1 On the Level of Acts

It is important to remember that narrative structure is not simply a consequence of the length of the text but of its complex structure where the acts work to produce a cumulative effect. Faulkner divides the story into five acts. The number of sentences in each act declares a relation between them and suggests a deliberate structure choice:

Table 2. Number of Sentences in each Act

\begin{tabular}{lc}
\hline Acts & No. of Sentences \\
\hline Act I & 46 \\
\hline Act II & 40 \\
\hline Act III & 44 \\
\hline Act IV & 44 \\
\hline Act V & 16 \\
\hline
\end{tabular}

The number of sentences in the first four acts is relatively consistent except for a noticeable shift in the fifth act. Faulkner operates this symmetry of structure for certain reasons: 
a. Change of narrator.

The narrator changes from one act to another regularly as shown below:

Table 3. Change of Narrator Through Acts

\begin{tabular}{cc}
\hline Acts & Narrator \\
\hline Act I & Old Aristocracy / Pre-Civil \\
\hline Act II & Post-War Generation \\
\hline Act III & A newer Rising Generation \\
\hline Act IV & A Composite Product \\
\hline Act V &
\end{tabular}

Table (3) demonstrations clearly how each act brings about a new generation who takes the role of narrating and running events.

\section{b. Change of Miss Emily's Status}

Accompanying the change of narrator, a new generation comes and with each new generation Emily is considered differently according to that generation, and the reader's impression about Emily is changed in parallel. In other words, the approximately symmetrical parallelism of acts declares a different relationship between Emily and her town: At her youth, Miss Emily is not wholly separated from her environment. In later life, however, she withdraws more and more until her own death again exposes her to townspeople:

Table 4. Miss Emily's Status Through Acts

\begin{tabular}{cl}
\hline Acts & Miss Emily's Status \\
\hline Act I & Emily is a duty \\
\hline Act II & Emily is a care \\
\hline Act III & Emily is neither nor a care \\
\hline Act IV & A Composite Product
\end{tabular}

It is clear that the structure of acts conveys a lot with its symmetry: the change of narrator, the change of Miss Emily's status, and the change of the reader's view are altered regularly in parallel with the shift of acts. However, the symmetricalness of the story is rounded out in Act $\mathrm{V}$ when the crowd comes to bury the corpse of the Yankee Homer Barron, Miss Emily's lover. Seemingly, Miss Emily no longer able to resist them as she did in all of the previous acts. This also comes in parallel with Miss Emily's indomitableness as a symbol of the Southern Aristocrat. The shorter closing of Act V reveals the invasion of the Aristocracy and the defeat of Miss Emily as a monument.

Faulkner uses a literary technique to create a seamless whole that makes the tale too interesting to stop reading: The lack of chronological order- particularly his own, unique way of telling a story. Unlike other writers of his era, such as John Steinbeck and Ernest Hemingway, who usually narrate their stories in a strictly linear progression, Faulkner violates all chronological sequences.

Using some facts and dates, the reader can build a framework on which to hang the following chronology:

Table 5. The Chronological Order of Events in Relation to Acts

\begin{tabular}{lc}
\hline \multicolumn{1}{c}{ EVENT } & ACT \\
\hline Miss Emily is born. & IV \\
\hline She and her father ride around the town in an old, elegant carriage. & II \\
\hline Her father dies, and for three days she refuses to acknowledge his death. & II \\
\hline Homer Barron arrives in town and begins to court & III \\
Miss Emily. & IV \\
\hline She buys a man's silver toilet set - a mirror, brush, and comb - and men's & \\
\hline
\end{tabular}


The town relegates her to disgrace and sends for her cousins. III

$\begin{array}{ll}\text { The cousins arrive, and Homer leaves town. IV } & \text { IV }\end{array}$

$\begin{array}{ll}\text { Three days after the cousins leave, Homer returns. IV } & \text { IV }\end{array}$

Miss Emily buys poison at the local drug store. III

$\begin{array}{ll}\text { Homer disappears. } & \text { IV }\end{array}$

A horrible stench envelops Miss Emily’s house. II

Four town aldermen secretly sprinkle lime on her lawn. II

Ironically, it can be seen from table (5) that when we reconstruct the chronological arrangement in this linear fashion, we render Faulkner's masterpiece an injustice. The order of events from a micro-vision attitude shows its impact on the whole story resulting in an element of suspense that dominates the story from as a whole.

\section{Conclusions}

As far as style is a choice, William Faulkner chooses complexity as a device in A Rose for Emily to create suspense and to deliver his themes skillfully. Complexity manifests itself in the story folds in many faces, mainly in sentence structure and acts structure as a whole. By applying Halliday's (1985) approach, it is concluded that it is a workable approach towards analyzing sentence complexity: Complex sentences carry the major themes triggered by the author. Most specifically, complex sentences (hypo \& para) accompany the speech and the actions of the main character in the story, Miss Emily, reflecting her complex character, complex thinking, and the complex life she leads. Complex and lengthy sentences can be very powerful: they are used to investigate an idea more thoroughly, give vivid descriptions, and develop tension; and the longest, most complex sentence in the story (of 129 words) represents the climax of the story. This is not to neglect the role of simple sentences which are tactfully functioned to stern minute details and shifts of time and place besides accompanying simple, short events.

The symmetricalness of acts shows another layer of stylistic complexity in parallel with each new generation, new narrator, new status of the heroine, and new perspectives on the behalf of the reader. From a more holistic perspective, functional complexity of the story structure according to Lauer, et al's (2008), reveals a well-knitted harmony between the streamline structure and the non-chronological order of events. Structure of a literary form proves to be another kind of meaning that pushes formal complexity into aesthetic experience. What is concluded is that Faulkner has aesthetically made the form a perfect vehicle for the content.

\section{References}

Alemu, A. (2015) Stylistic Analysis of Selected Short Stories By O Henry. Addis Ababa University. A Published Thesis.

Bellard, C. (1992) The Literary Stylistics of French: An Introductory Guide. Manchester University Press.

Carter, R. (1997) Investigating English Discourse: Language, Literacy and Literature. London: Routledge.

Clay, M. (2005). "A Rose for Emily: Oral Plot, Typographic Story". Storytelling: A Critical Journal of Popular Narrative. Vol 5. No.1. pp. 80-93.

Dámová, P. (2007) The Language of Law - A Stylistic Analysis with a Focus on Lexical (Binomial) Expressions. Masaryk University in Brno Faculty of Education Department of English Language and Literature. A Published Thesis. Dove, G. (1989) Suspense in the Formula Story. Bowling Green State University Popular Press.

Fabb, N. (2002) Language and Literary Structure: The Linguistic Analysis in Verse and Narration. Cambridge: Cambridge University Press.

(2005) "Linguistics in a department of English Literature". English Subject Center Newsletter. The Higher Educational Academy. Issue 8, pp. 5-9.

Furlong, A. (2014) "Outsourcing: A Relevance-Theoretic Account of the Interpretation of Theatrical Texts". In Chapman, S. and Clark, B. Palgrave (eds.) Pragmatic Literary Stylistics. Palgrave Studies in Pragmatics, Language and Cognition, pp. 70-90.

Gass, H. (1985) Habitations of the Word: Essays. New york: Simon and Schuster.

Glenn, W. (2004) "Form Follows Function: The Relationship Between Structure and Content in Three of Karen Hesse's Novels". The Alan Review. Vol. 31, no 2, pp. 27- 33.

Halliday, M.A.K. (1971) "Linguistic function and literary style: an enquiry into the language of William Golding's 'The Inheritors'". In S. Chatman (ed.) Literary Style: a symposium. New York: Oxford University Press. 
Hişmanoğlu, M. (2005) "Teaching English Through Literature". Journal of Language and Linguistic Studies. Vol.1, no.1, pp. 53-67.

Jucker, H. (1992) Social Stylistics: Syntactic Variation in British Newspapers. Walter de Gruyter.

Nakagawa, E. and Oquendo, F. (2013) "Perspectives and challenges of reference architectures in multi software product line". First International Workshop on Multi Product Line Engineering. Tokio, Japan, pp. 100-103.

Lauer, G.; Winko, S.; Schwager, M.; Webelhuth, G.; Lass, U.; Mattler, U. (2008) Micro and Macro Level Structures in Written Discourse. Courant Research Centre, Grant Proposal, University Göttingen.

Leech, G. (1969) A Linguistic Guide to English Poetry. London: Longman.

Olson, A.; George, J.; and Ray, R. (1985) Style and Readability in Business Writing: A Sentence-Combining Approach. New York: Random House.

Patton, M. and Meara, N. (1987) "The Analysis of Natural Language in Psychological Treatment". In Robert L. Russell (ed.) Language in Psychotherapy: Strategies of Discovery. pp. 273-301. New York, Springer Science \& Business Media.

Perinbanayagam, R. (1991) Discursive Acts: Language, Signs, and Selves. $2^{\text {nd }}$ ed. USA: Aldine Transaction Publishers.

Roberts, L. (1997) Faulkner's Short Stories. Hungary: Minds, Inc.

SparkNotes Editors. (2007). SparkNote on A Rose for Emily. Retrieved on May 25, 2015, from http://www.sparknotes.com/short-stories/a-rose-for-emily/

Volpe, E. (2004) A Readers Guide to William Faulkner: The Short Stories. New York: Syracuse University Press.

Wales, K. (2011) A Dictionary of Stylistics. $3^{\text {rd }}$ ed. Routledge, Taylor and Francis Group.

Appendix

TABLE (1) Sentence Structure and Sentence Length in ACT I

\begin{tabular}{|c|c|c|c|c|}
\hline $\begin{array}{l}\text { SENTENCE } \\
\text { NO. }\end{array}$ & $\begin{array}{l}\text { SENTENCE } \\
\text { LENGTH }\end{array}$ & $\begin{array}{c}\text { CLAUSE TYPE } \\
\text { SIMPLE/COMPLEX }\end{array}$ & $\begin{array}{c}\text { COMPLEXITY } \\
\text { TYPE PARA / HYPO }\end{array}$ & $\begin{array}{c}\text { SENTENCE } \\
\text { REPRESENTATION }\end{array}$ \\
\hline 1 & 12 & COMPLEX & HYPO & $\beta^{\wedge} \alpha$ \\
\hline 2 & 45 & COMPLEX & HYPO & $\alpha^{\wedge} \beta$ \\
\hline 3 & 38 & COMPLEX & HYPO & $\alpha^{\wedge} \beta^{\wedge} \gamma$ \\
\hline 4 & 40 & COMPLEX & PARA-HYPO & $1 \wedge 2 \wedge 3 \alpha 3 \beta$ \\
\hline 5 & 40 & COMPLEX & HYPO & $\alpha^{\wedge} \beta^{\wedge} \gamma$ \\
\hline 6 & 62 & COMPLEX & PARA-HYPO & $1^{\wedge} 2 \alpha 2 \beta 2 \beta \beta 12 \beta \beta 2^{\wedge} 2 \gamma 2 \delta$ \\
\hline 7 & 8 & COMPLEX & HYPO & $\alpha^{\wedge} \beta$ \\
\hline 8 & 32 & COMPLEX & HYPO & $\alpha^{\wedge} \beta^{\wedge} \gamma$ \\
\hline 9 & 21 & COMPLEX & PARA & $1^{\wedge} 2$ \\
\hline 10 & 19 & COMPLEX & HYPO & $\beta^{\wedge} \alpha$ \\
\hline 11 & 12 & SIMPLE & & \\
\hline 12 & 7 & COMPLEX & PARA & $1^{\wedge} 2$ \\
\hline 13 & 16 & COMPLEX & HYPO & $\alpha^{\wedge} \beta$ \\
\hline 14 & 49 & COMPLEX & HYPO & $1 \alpha^{\wedge} 1 \beta^{\wedge} 2 \alpha^{\wedge} 2 \beta$ \\
\hline 15 & 8 & SIMPLE & & \\
\hline 16 & 10 & SIMPLE & & \\
\hline 17 & 26 & COMPLEX & HYPO & \\
\hline 18 & 19 & COMPLEX & HYPO & $1^{\wedge} 2 \alpha^{\wedge} 2 \beta^{\wedge} 2 \gamma$ \\
\hline 19 & 10 & SIMPLE & & $\alpha^{\wedge} \beta$ \\
\hline 20 & 7 & SIMPLE & & \\
\hline 21 & 8 & SIMPLE & & \\
\hline 22 & 39 & COMPLEX & PARA-HYPO & \\
\hline 23 & 16 & SIMPLE & & $1 \beta^{\wedge} 1 \alpha^{\wedge} 1 \alpha \alpha$ \\
\hline 24 & 35 & COMPLEX & HYPO & \\
\hline 25 & 21 & COMPLEX & HYPO & $\alpha^{\wedge} \beta$ \\
\hline 26 & 16 & SIMPLE & & $1^{\wedge} 2 \alpha^{\wedge} 2 \beta^{\wedge} 2 \beta \beta 1$ \\
\hline 27 & 37 & COMPLEX & HYPO & \\
\hline 28 & 7 & SIMPLE & & $\beta^{\wedge} \alpha^{\wedge} \alpha \alpha 1^{\wedge} \alpha \alpha 2^{\wedge} \gamma$ \\
\hline 29 & 17 & COMPLEX & PARA-HYPO & \\
\hline 30 & 15 & COMPLEX & HYPO & $2 \alpha^{\wedge} 2 \beta$ \\
\hline 31 & 6 & SIMPLE & & $\alpha^{\wedge} \beta$ \\
\hline 32 & 6 & SIMPL & & \\
\hline 33 & 6 & SIMPLE & & \\
\hline 34 & 14 & COMPLEX & PARA & \\
\hline 35 & 3 & SIMPLE & & \\
\hline
\end{tabular}




\begin{tabular}{|c|c|c|c|c|}
\hline $\begin{array}{l}36 \\
37 \\
38 \\
39 \\
40 \\
41 \\
42 \\
43 \\
44 \\
45 \\
46 \\
\end{array}$ & $\begin{array}{c}7 \\
11 \\
8 \\
6 \\
6 \\
17 \\
3 \\
6 \\
6 \\
8 \\
7 \\
\end{array}$ & $\begin{array}{c}\text { SIMPLE } \\
\text { COMPLEX } \\
\text { COMPLEX } \\
\text { SIMPLE } \\
\text { SIMPLE } \\
\text { COMPLEX } \\
\text { SIMPLE } \\
\text { SIMPLE } \\
\text { SIMPLE } \\
\text { SIMPLE } \\
\text { SIMPLE } \\
\end{array}$ & $\begin{array}{l}\text { HYPO } \\
\text { PARA } \\
\text { PARA }\end{array}$ & $\begin{array}{c}\alpha^{\wedge} \beta \\
1^{\wedge} 2 \\
1^{\wedge} 2^{\wedge} 3\end{array}$ \\
\hline 46 & 812 & $21 / 25$ & $9 / 20$ & \\
\hline
\end{tabular}

TABLE (2) Sentence Structure and Sentence Length in ACT II

\begin{tabular}{|c|c|c|c|c|}
\hline $\begin{array}{l}\text { SENTENCE } \\
\text { NO. }\end{array}$ & $\begin{array}{l}\text { SENTENCE } \\
\text { LENGTH }\end{array}$ & $\begin{array}{l}\text { CLAUSE TYPE } \\
\text { SIMPLE / } \\
\text { COMPLEX }\end{array}$ & $\begin{array}{c}\text { COMPLEXITY } \\
\text { TYPE PARA / } \\
\text { HYPO }\end{array}$ & $\begin{array}{c}\text { SENTENCE } \\
\text { REPRESENTATION }\end{array}$ \\
\hline 1 & 20 & COMPLEX & HYPO & $\alpha^{\wedge} \beta$ \\
\hline 2 & 25 & COMPLEX & НYPO & $11 \alpha \alpha 11 \alpha \alpha 2^{\wedge} 2$ \\
\hline 3 & 20 & COMPLEX & PARA-HYPO & $1^{\wedge} 2 \beta^{\wedge} 2 \alpha$ \\
\hline 4 & 39 & COMPLEX & PARA-HYPO & $1^{\wedge} 2^{\wedge} 3 \alpha^{\wedge} 3 \beta$ \\
\hline 5 & 24 & COMPLEX & PARA-HYPO & $1^{\wedge} 2^{\wedge} 3 \alpha^{\wedge} 3 \beta$ \\
\hline 6 & 15 & SIMPLE & & \\
\hline 7 & 13 & SIMPLE & & \\
\hline 8 & 12 & COMPLEX & PARA & $1^{\wedge} 2$ \\
\hline 9 & 10 & COMPLEX & PARA & $1^{\wedge} 2$ \\
\hline 10 & 4 & SIMPLE & & \\
\hline 11 & 9 & COMPLEX & PARA-HYPO & $1 \alpha^{\wedge} 1 \beta^{\wedge} 2$ \\
\hline 12 & 16 & COMPLEX & HYPO & $1 \alpha^{\wedge} 1 \beta$ \\
\hline 13 & 6 & SIMPLE & & \\
\hline 14 & 17 & COMPLEX & PARA-HYPO & $1^{\wedge} 2 \alpha^{\wedge} 2 \beta$ \\
\hline 15 & 8 & SIMPLE & & \\
\hline 16 & 18 & COMPLEX & PARA-HYPO & $1 \alpha^{\wedge} 1 \beta^{\wedge} 2$ \\
\hline 17 & 19 & SIMPLE & & \\
\hline 18 & 5 & COMPLEX & PARA & $1^{\wedge} 2$ \\
\hline 19 & 9 & COMPLEX & HYPO & $\alpha^{\wedge} \beta$ \\
\hline 20 & 13 & COMPLEX & PARA-HYPO & $1 \alpha^{\wedge} 1 \beta^{\wedge} 2$ \\
\hline 21 & 16 & COMPLEX & PARA & $1^{\wedge} 2^{\wedge} 3$ \\
\hline 22 & 50 & COMPLEX & PARA-HYPO & $1^{\wedge} 2 \alpha^{\wedge} 2 \alpha \alpha^{\wedge} 2 \beta^{\wedge} 2 \beta \beta 1$ \\
\hline 23 & 15 & COMPLEX & PARA & $1^{\wedge} 2$ \\
\hline 24 & 33 & COMPLEX & PARA-HYPO & $1 \beta^{\wedge} 1 \alpha \beta^{\wedge} 1 \alpha^{\wedge} 2$ \\
\hline 25 & 17 & COMPLEX & HYPO & $\alpha^{\wedge} \beta$ \\
\hline 26 & 9 & SIMPLE & & \\
\hline 27 & 12 & COMPLEX & HYPO & \\
\hline 28 & 33 & COMPLEX & HYPO & $\alpha^{\wedge} \beta$ \\
\hline 29 & 14 & SIMPLE & & $\alpha \alpha 1^{\wedge} \alpha \alpha 2^{\wedge} \alpha^{\wedge} \beta^{\wedge} \beta \beta$ \\
\hline 30 & 46 & COMPLEX & HYPO & \\
\hline 31 & 38 & COMPLEX & PARA-HYPO & $\alpha^{\wedge} \beta^{\wedge} \gamma^{\wedge} \varepsilon$ \\
\hline 32 & 24 & COMPLEX & PARA-HYPO & $1 \beta^{\wedge} 2^{\wedge} 1 \alpha^{\wedge} 3 \alpha^{\wedge} 3 \beta$ \\
\hline 33 & 7 & SIMPLE & & $1 \beta^{\wedge} 1 \alpha^{\wedge} 1 \alpha \alpha 1^{\wedge} 1 \alpha \alpha 2^{\wedge} 2$ \\
\hline 34 & 10 & COMPLEX & HYPO & \\
\hline 35 & 18 & COMPLEX & HYPO & $1^{\wedge} 2^{\wedge} 3 \gamma^{\wedge} 3 \alpha^{\wedge} 3 \beta$ \\
\hline 36 & 42 & COMPLEX & PARA-HYPO & $\alpha^{\wedge} \beta$ \\
\hline 37 & 9 & COMPLEX & HYPO & $\alpha^{\wedge} \beta$ \\
\hline 38 & 26 & COMPLEX & HYPO & $\alpha^{\wedge} \beta^{\wedge} \gamma^{\wedge} \gamma \gamma$ \\
\hline 39 & 20 & COMPLEX & PARA-HYPO & $1 \beta^{\wedge} 1 \alpha^{\wedge} 2$ \\
\hline 40 & 8 & COMPLEX & HYPO & $\alpha^{\wedge} \beta$ \\
\hline & & & & $1 \alpha^{\wedge} 1 \beta^{\wedge} 2 \alpha^{\wedge} 2 \beta^{\wedge} 2 \beta \beta^{\wedge} 2 \gamma$ \\
\hline 40 & 749 & $9 / 31$ & $18 / 26$ & \\
\hline
\end{tabular}


TABLE (3) Sentence Structure and Sentence Length in ACT III

\begin{tabular}{|c|c|c|c|c|}
\hline $\begin{array}{l}\text { SENTENCE } \\
\text { NO. }\end{array}$ & $\begin{array}{l}\text { SENTENCE } \\
\text { LENGTH }\end{array}$ & $\begin{array}{c}\text { SENTENCE TYPE } \\
\text { SIMPLE / } \\
\text { COMPLEX }\end{array}$ & $\begin{array}{c}\text { COMPLEXITY } \\
\text { TYPE PARA / } \\
\text { HYPO }\end{array}$ & $\begin{array}{c}\text { SENTENCE } \\
\text { REPRESENTATION }\end{array}$ \\
\hline 1 & 7 & SIMPLE & & \\
\hline 2 & 32 & COMPLEX & HYPO & $\beta^{\wedge} \alpha^{\wedge} \alpha \alpha$ \\
\hline 3 & 23 & COMPLEX & PARA & $1^{\wedge} 2$ \\
\hline 4 & 33 & SIMPLE & & \\
\hline 5 & 26 & COMPLEX & PARA-HYPO & $1 \alpha^{\wedge} 1 \beta^{\wedge} 2$ \\
\hline 6 & 7 & SIMPLE & & \\
\hline 7 & 21 & COMPLEX & HYPO & $\beta \wedge \alpha$ \\
\hline 8 & 28 & COMPLEX & НYРO & $\alpha \wedge \beta$ \\
\hline 9 & 31 & COMPLEX & НYPO & $\alpha \wedge \beta \wedge \gamma \wedge \varepsilon$ \\
\hline 10 & 27 & COMPLEX & HYPO & $\alpha \wedge \beta \wedge \gamma$ \\
\hline 11 & 5 & SIMPLE & & \\
\hline 12 & 7 & SIMPLE & & \\
\hline 13 & 35 & COMPLEX & PARA & \\
\hline 14 & 9 & SIMPLE & & $1 \wedge 2 \wedge 3$ \\
\hline 15 & 13 & COMPLEX & PARA & \\
\hline 16 & 11 & COMPLEX & PARA & $1 \wedge 2$ \\
\hline 17 & 4 & SIMPLE & & $1 \wedge 2$ \\
\hline 18 & 3 & SIMPLE & & \\
\hline 19 & 33 & COMPLEX & HYPO & \\
\hline 20 & 14 & COMPLEX & HYPO & $\alpha \wedge \beta \wedge \gamma$ \\
\hline 21 & 31 & COMPLEX & PARA-HYPO & $\alpha \wedge \beta \wedge \gamma$ \\
\hline 22 & 9 & SIMPLE & & $1 \alpha \wedge 1 \beta \wedge 2 \alpha \wedge 2 \beta$ \\
\hline 23 & 22 & COMPLEX & PARA-HYPO & \\
\hline 24 & 9 & COMPLEX & PARA & $1 \alpha \wedge 1 \beta \wedge 2$ \\
\hline 25 & 44 & COMPLEX & НYPO & $1 \wedge 2$ \\
\hline 26 & 6 & COMPLEX & PARA & $\alpha \wedge \beta \wedge \gamma$ \\
\hline 27 & 11 & SIMPLE & & $1 \wedge 2$ \\
\hline 28 & 6 & COMPLEX & НYРО & \\
\hline 29 & 5 & SIMPLE & & $\alpha \wedge \beta$ \\
\hline 30 & 4 & SIMPLE & & \\
\hline 31 & 7 & SIMPLE & & \\
\hline 32 & 9 & COMPLEX & PARA & \\
\hline 33 & 5 & SIMPLE & & $1 \wedge 2$ \\
\hline 34 & 4 & SIMPLE & & \\
\hline 35 & 4 & SIMPLE & & \\
\hline 36 & 3 & SIMPLE & & \\
\hline 37 & 6 & SIMPLE & & \\
\hline 38 & 12 & SIMPLE & & \\
\hline 39 & 6 & SIMPLE & & \\
\hline 40 & 5 & COMPLEX & PARA & \\
\hline 41 & 15 & COMPLEX & PARA & $\beta \wedge \alpha$ \\
\hline 42 & 32 & COMPLEX & PARA-HYPO & $\alpha \wedge \beta$ \\
\hline 43 & 13 & COMPLEX & PARA & $1 \wedge 2 \alpha \wedge 2 \beta \wedge 3 \wedge 4 \wedge 5 \wedge 6$ \\
\hline 44 & 20 & COMPLEX & HYPO & $1 \wedge 2$ \\
\hline & & & & $\beta \wedge \alpha$ \\
\hline 44 & 657 & $20 / 24$ & $14 / 14$ & \\
\hline
\end{tabular}

TABLE (4) Sentence Structure and Sentence Length in ACT IV

\begin{tabular}{|c|c|c|c|c|}
\hline $\begin{array}{c}\text { SENTENCE } \\
\text { NO. }\end{array}$ & $\begin{array}{c}\text { SENTENCE } \\
\text { LENGTH }\end{array}$ & $\begin{array}{c}\text { SENTENCE TYPE } \\
\text { SIMPLE / } \\
\text { COMPLEX }\end{array}$ & $\begin{array}{c}\text { COMPLEXITY } \\
\text { TYPE PARA / } \\
\text { HYPO }\end{array}$ & $\begin{array}{c}\text { SENTENCE } \\
\text { REPRESENTATION }\end{array}$ \\
\hline 1 & 20 & COMPLEX & PARA & $1 \wedge 2 \wedge 3 \wedge 4$ \\
2 & 18 & COMPLEX & PARA-HYPO & $1 \beta \wedge 1 \alpha \wedge 2$ \\
3 & 38 & COMPLEX & PARA-HYPO & $1 \wedge 2 \alpha \wedge 2 \beta \wedge 2 \gamma \wedge 3 \alpha \wedge 3 \beta \wedge 2 \varepsilon$ \\
4 & 44 & COMPLEX & HYPO & $\alpha \wedge \beta$ \\
5 & 24 & COMPLEX & HYPO & $\alpha \wedge \beta$ \\
6 & 25 & COMPLEX & PARA & $1 \wedge 2 \wedge 3$ \\
7 & 16 & COMPLEX & PARA & $1 \wedge 2$ \\
8 & 23 & COMPLEX & PARA & $1 \wedge 2$ \\
9 & 16 & COMPLEX & PARA & $1 \wedge 2$ \\
\hline
\end{tabular}




\begin{tabular}{|c|c|c|c|c|}
\hline 10 & 4 & SIMPLE & & \\
\hline 11 & 10 & COMPLEX & HYPO & $\alpha \wedge \beta$ \\
\hline 12 & 26 & COMPLEX & PARA-HYPO & $1 \alpha \wedge 1 \beta \wedge 2$ \\
\hline 13 & 24 & COMPLEX & PARA-HYPO & $1 \alpha \wedge 1 \beta \wedge 2 \wedge 3$ \\
\hline 14 & 4 & SIMPLE & & \\
\hline 15 & 18 & COMPLEX & HYPO & \\
\hline 16 & 18 & COMPLEX & HYPO & $\alpha \wedge \beta \wedge \beta \beta$ \\
\hline 17 & 39 & COMPLEX & PARA-HYPO & $\alpha \wedge \alpha \alpha \wedge \beta$ \\
\hline 18 & 19 & COMPLEX & PARA-HYPO & $1 \alpha \wedge 1 \beta \wedge 2 \alpha \wedge 2 \beta \wedge 2 \beta \beta 1 \wedge 2 \beta \beta 2 \wedge 2 \beta \beta 3$ \\
\hline 19 & 7 & SIMPLE & & $1 \wedge 2 \alpha \wedge 2 \beta$ \\
\hline 20 & 16 & COMPLEX & HYPO & \\
\hline 21 & 16 & COMPLEX & PARA & $\beta \wedge \alpha$ \\
\hline 22 & 17 & SIMPLE & & $1 \wedge 2$ \\
\hline 23 & 17 & COMPLEX & PARA & \\
\hline 24 & 36 & COMPLEX & PARA-HYPO & $1 \wedge 2$ \\
\hline 25 & 35 & COMPLEX & PARA-HYPO & $1 \alpha \wedge 1 \beta \wedge 1 \gamma \wedge 2$ \\
\hline 26 & 16 & COMPLEX & PARA-HYPO & $1 \alpha \wedge 1 \beta \wedge 2 \alpha \wedge 2 \beta$ \\
\hline 27 & 24 & COMPLEX & HYPO & $1 \beta \wedge 1 \alpha \wedge 2$ \\
\hline 28 & 24 & SIMPLE & & $\alpha \wedge \beta \wedge \gamma$ \\
\hline 29 & 31 & COMPLEX & НYPO & \\
\hline 30 & 51 & COMPLEX & HYPO & \\
\hline 31 & 6 & SIMPLE & & $\alpha \wedge \beta \wedge \gamma$ \\
\hline 32 & 44 & COMPLEX & PARA-HYPO & $\alpha \wedge \beta \wedge \gamma$ \\
\hline 33 & 13 & COMPLEX & PARA & \\
\hline 34 & 27 & COMPLEX & HYPO & $1 \wedge 2 \wedge 3 \wedge 4 \alpha \wedge 4 \beta$ \\
\hline 35 & 6 & SIMPLE & & $1 \wedge 2$ \\
\hline 36 & 20 & COMPLEX & HYPO & $\beta \wedge \alpha$ \\
\hline 37 & 20 & COMPLEX & НYPO & \\
\hline 38 & 45 & COMPLEX & НYPO & \\
\hline 39 & 13 & SIMPLE & & $\alpha \wedge \beta$ \\
\hline 40 & 41 & SIMPLE & & $\alpha \wedge \beta \wedge \gamma$ \\
\hline 41 & 20 & COMPLEX & HYPO & $\alpha \wedge \alpha \alpha \wedge \beta \wedge \gamma$ \\
\hline 42 & 22 & COMPLEX & PARA-HYPO & \\
\hline 43 & 22 & COMPLEX & HYPO & \\
\hline 44 & 32 & & PARA & $\begin{array}{c}\alpha \wedge \beta \wedge \gamma \wedge \gamma \gamma \\
1 \alpha \wedge 1 \beta \wedge 2 \alpha \wedge 2 \beta \wedge 2 \beta \beta \\
\alpha \wedge \beta \\
1 \wedge 2\end{array}$ \\
\hline 44 & 1007 & $8 / 36$ & $20 / 27$ & \\
\hline
\end{tabular}

TABLE (5) Sentence Structure and Sentence Length in ACT V

\begin{tabular}{|c|c|c|c|c|}
\hline $\begin{array}{l}\text { SENTENCE } \\
\text { NO. }\end{array}$ & $\begin{array}{l}\text { SENTENCE } \\
\text { LENGTH }\end{array}$ & $\begin{array}{l}\text { SENTENCE TYPE } \\
\text { SIMPLE / } \\
\text { COMPLEX }\end{array}$ & $\begin{array}{l}\text { COMPLEXITY } \\
\text { TYPE PARA / } \\
\text { HYPO }\end{array}$ & $\begin{array}{c}\text { SENTENCE } \\
\text { REPRESENTATION }\end{array}$ \\
\hline 1 & 30 & COMPLEX & PARA & $1 \wedge 2$ \\
\hline 2 & 15 & COMPLEX & PARA & $1 \wedge 2$ \\
\hline 3 & 7 & SIMPLE & & \\
\hline 4 & 129 & COMPLEX & HYPO & $\alpha \wedge \beta \wedge \gamma \wedge \varepsilon \wedge \delta \wedge \zeta \wedge \eta \wedge \theta \wedge \kappa \wedge \lambda \wedge \mu \wedge v$ \\
\hline 5 & 28 & COMPLEX & HYPO & $\alpha \wedge \beta \wedge \gamma \wedge \varepsilon$ \\
\hline 6 & 14 & COMPLEX & HYPO & $\alpha \wedge \beta \wedge \gamma$ \\
\hline 7 & 15 & SIMPLE & & \\
\hline 8 & 62 & COMPLEX & HYPO & $\alpha \wedge \beta \wedge \gamma \wedge \varepsilon$ \\
\hline 9 & 26 & COMPLEX & HYPO & $\alpha \wedge \beta \wedge \gamma \wedge \varepsilon$ \\
\hline 10 & 18 & COMPLEX & PARA & $1 \wedge 2$ \\
\hline 11 & 7 & SIMPLE & & \\
\hline 12 & 16 & COMPLEX & HYPO & $\alpha \wedge \beta$ \\
\hline 13 & 30 & COMPLEX & PARA-HYPO & $1 \alpha \wedge 2 \alpha \wedge 2 \beta \wedge 1 \beta$ \\
\hline 14 & 42 & COMPLEX & PARA-HYPO & $1 \beta \wedge 1 \alpha \wedge 1 \alpha \alpha 1 \wedge 1 \alpha \alpha 2 \wedge 1 \beta \wedge 2$ \\
\hline 15 & 14 & COMPLEX & HYPO & $\alpha \wedge \beta$ \\
\hline 16 & 30 & COMPLEX & PARA & $1 \wedge 2 \wedge 3$ \\
\hline 16 & 483 & $3 / 13$ & $5 / 10$ & \\
\hline
\end{tabular}

